$1-1-1936$

\title{
Color of lean of beef as affected by grass and grain feeding
}

\author{
J. H. Longwell
}

Follow this and additional works at: https://researchrepository.wvu.edu/ wv_agricultural_and_forestry_experiment_station_bulletins

\section{Digital Commons Citation}

Longwell, J. H., "Color of lean of beef as affected by grass and grain feeding" (1936). West Virginia Agricultural and Forestry Experiment Station Bulletins. 274.

https://researchrepository.wvu.edu/wv_agricultural_and_forestry_experiment_station_bulletins/275 @ WVU. It has been accepted for inclusion in West Virginia Agricultural and Forestry Experiment Station Bulletins by an authorized administrator of The Research Repository @ WVU. For more information, please contact ian.harmon@mail.wvu.edu. 



\section{COLOR OF LEAN OF BEEF as Affected by}

\section{GRASS AND GRAIN FEEDING}

by J. H. LONGWELL

AGRICULTURAL EXPERIMENT STATION COLLEGE OF AGRICULTURE, WEST VIRGINIA UNIVERSITY F. D. FROMME, Director MORGANTOWN 


\title{
Color of Lean of Beef as Affected by Grass and Grain Feeding
}

\author{
by J. H. LONGWELL
}

$\mathrm{C}$

ONSUMERS OF BEEF generally object to dark-colored lean, preferring a bright-red color. This objection to dark beef probably is based on the impression that the beef is dark because it was produced by an inferior animal, or because it was handled improperly at the time of or subsequent to slaughter, and that as a result of one or both of ihese factors the beef will be less desirable. For this reason the retailer usually is forced to sell dark beef at a lower price than bright beef. The retailer in turn is unwilling to pay the meat packer as much for dark as for bright beef. No external characteristic of the live animal is known to be an indication of the color of the beef which the animal will proauce. Justifiably or not, the packer commonly attributes dark color in beef to the use of grass as a feed.

Grass-finished cattle commonly are penalized on the market because of the widespread opinion among meat packers and retailer's that the beef will be dark. Because of this almost universal objection to grassfed cattle, West Virginia eattlemen, as well as those in adjoining states, often are forced to accept a lower price for their cattle than for grainfed cattle of similar grade.

The experimental cattle-feeding work which has been carried on at Morgantown and Lewisburg has provided material which may help to answer the question of the effect of feed on the color of beef.

Color readings were made on beef samples from fat yearlings, 2-year-old, and 3-year-old cattle. The yearlings, all of which were fed at Morgantown, included eight good and choice grade native steer's slaughtered in August, 1930, one Angus heifer slaughtered in December, 1929, and one Shorthorn and two Angus steers slaughtered in October, 1930. All these eattle were grain-fed and highly finished.

The two-year-old cattle fed at Morgantown included eight grade native steers slaughtered in November, 1930, and 30 grade native steers slaughtered in October, 1931. The eight steers in 1930 were on pasture alone from May 1st until September 4th, then were full-fed a ration consisting of eracked corn (16.66 parts) and cottonsecd oilmeal (one part), with hay, in dry-lot for 56 days. The 30 steers fed in 1931 weredivided into three lots of ten head each about May 1st and were fed as follows :

Lot 1-grass alone, 56 days; grain on grass, 140 days.

Lot 2-grass alone, 84 days; grain on grass, 112 days.

Lot 3 -grass alone, 140 days; grain in dry lot, 56 days.

Lots 1 and 2 received the same total amount of grain until September 4th. After this date all three lots received all the grain they would clean up readily for the last 56 days of the experiment. The grain mixture consisted of six parts cracked corn and one part cottonseed meal. 
The two-year-old cattle fed at Lewisburg included 50 stcer's in each of the three ycars, 1929, 1930, and 1931. With the exception of 12 western steers, all these cattle were grade native steers purchased in the fall and carried through the winter on corn silage, straw or hay, and cottonseed oilmeal.

About May 1st each year these stcer's were divided into five lots of ten head each and fed as follows:

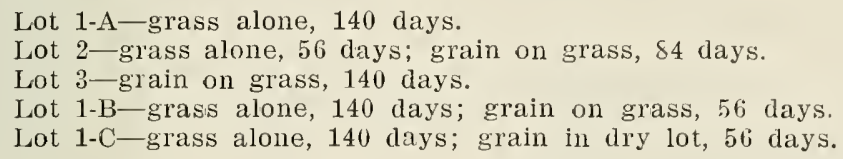

The grain consisted of shelled corn (eight parts) and cottonseed meal (one part).

In 1929 all ten steers in Lot 1 -A were slaughtered and color readings made on the beef, but beef from only five steers from each of the other four lots was available for color determinations. In 1930 and 1931 all ten steers in each lot were slaughtered and color readings made on the beef.

The three-year-old steers at Morgantown were purchased as calves and received no grain at any time except the small amounts of oilmeal fed during the winter. They were fattened on grass and sold at the end of the grazing period.

The carcasses from all these cattle were inspected, and samples were obtained from the rib eye for color determinations. Nearly all samples were taken from the right rib eye near the twelfth rib. In a few cases it was necessary to take the sample near the eighth rib.

The color values of each sample of lean beef were determined from data obtained with a spectrophotometer or color analyzer. This instrument is used to measure the amount of a standard light reflected from the sample at sclected intervals through the entire visible spectrum. From these data the color values are calculated. The values so calculated constitute a complete description of the color of a sample of beef. These values are absolute, the errors being eliminated that would be introduced by estimating the color with the eye. Once obtained, the values may be compared with values of samples taken at another time, thus making it possible to compare the colors of meat produced at widely separated times.

The color values are expressed in terms of dominant hue, purity or intensity, and relative brightness. Most naturally occurring colors consist of mixtures of two or more of the seven primary hues, violet, blue, blue-green, green, yellow, orange, and red. Usually one of these hues will dominate all the others and will be the principal hue affecting the color. This is the dominant hue, and it is expressed in millimicrons wave length. This dominant hue may be present in varying amounts, the amount determining the intensity or purity of the color. The intensity is expressed in percentage of this hue. The relative brightness refers to the brightness of the color compared with noon-day sunlight. 
It is expressed in percentage. In beef color the relative brightness is related more closely to the color of beef as the eye sees it than is either hue or intensity. Brightness values of 11 or above represent bright beef, between 9 and 11, medium bright, and below 9. dark beef. Extremely dark beef, or beef from what commonly are called "black cutters," has brightness values of 7 or less.

TABLE 1-Color values of the beef from fat yearlings grain-fed at Morgantown

\begin{tabular}{c|c|cc}
\hline \hline Animal No. & Hue & Intensity & Brightness \\
\hline 21 & 596 & 27 & 12.24 \\
22 & 593 & 32 & 11.50 \\
23 & 603 & 24 & 10.93 \\
24 & 605 & 20 & 9.92 \\
25 & 602 & 29 & 13.03 \\
26 & 604 & 20 & 12.06 \\
27 & 597 & 26 & 13.13 \\
28 & 590 & 44 & 14.04 \\
Angus heifer & 603 & 23 & 11.40 \\
Shorthorn steer & 605 & 32 & 12.97 \\
Angus steer & 607 & 25 & 12.57 \\
Angus steer & 600 & 27 & 12.18 \\
Average & 600.4 & 27.4 & 12.16 \\
\hline \hline
\end{tabular}

TABLE 2-Color values of the beef from Z-year-old steers fed at Morgantown on grass alone (127 days) and grain and hay in dry lot (56 days), 1330

\begin{tabular}{c|c|c|c}
\hline Animal No. & Hue & Intensity & Brightness \\
\hline 9 & 599 & 26 & 10.65 \\
10 & 625 & 14 & 11.34 \\
11 & 610 & 20 & 10.84 \\
12 & 625 & 13 & 11.13 \\
13 & 604 & 20 & 10.88 \\
14 & 607 & 16 & 12.14 \\
15 & 603 & 24 & 10.91 \\
16 & 606 & 20 & 11.07 \\
Average & 610 &
\end{tabular}

In some dark samples not only is the brightness value low, but there is an excess of blue and a deficiency of red, the resulting color being purple. The hue of such a purple is expressed as the blue complement of the color. Fol example stecr 1, Lot 1-B, 1931, (Table 5) from the Lewisburg cattle had a hue value expressed as 491-C. This means that wave length 491 , in the blue part of the spectrum, is one of two dominant hues, the other being red, and the resulting color being purple. The hue values for those samples having a purple color are not included in the averages because this color is a combination of two hues which cannot be averaged.

1 to 5 .

The color values for all the beef samples used are given in Tables

The numbers of yearlings (Table 1) and three-year-old steers (Table 4) are not large enough to warrant definite conclusions. None of the three-year-old steer's killed dark even though nearly all their growth and finish were produced on grass.

Comparison of the two-year-old steers fed at Morgantown (Tables 2 and 3 ) shows no appreciable differences in brightness, which is the 


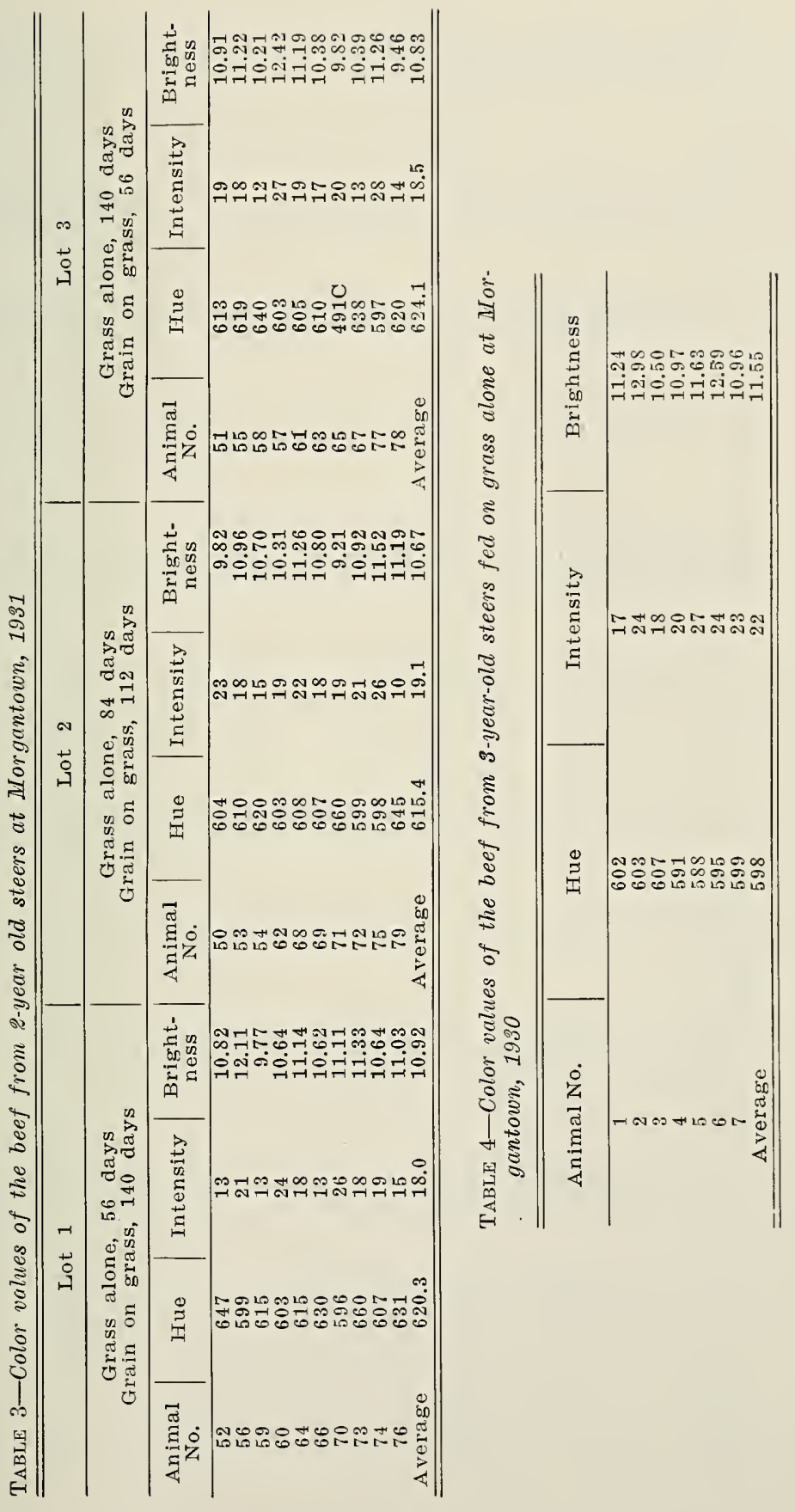




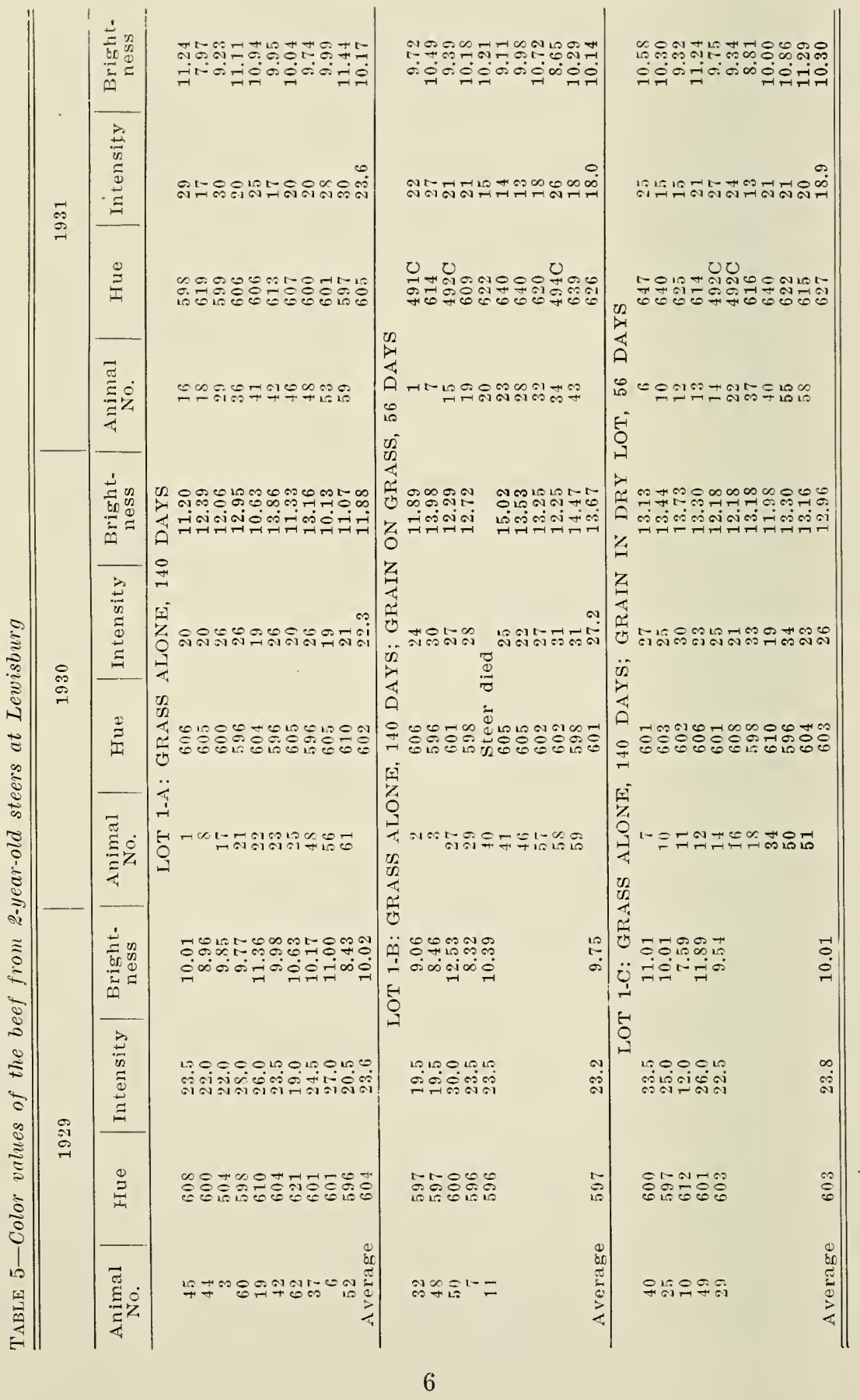




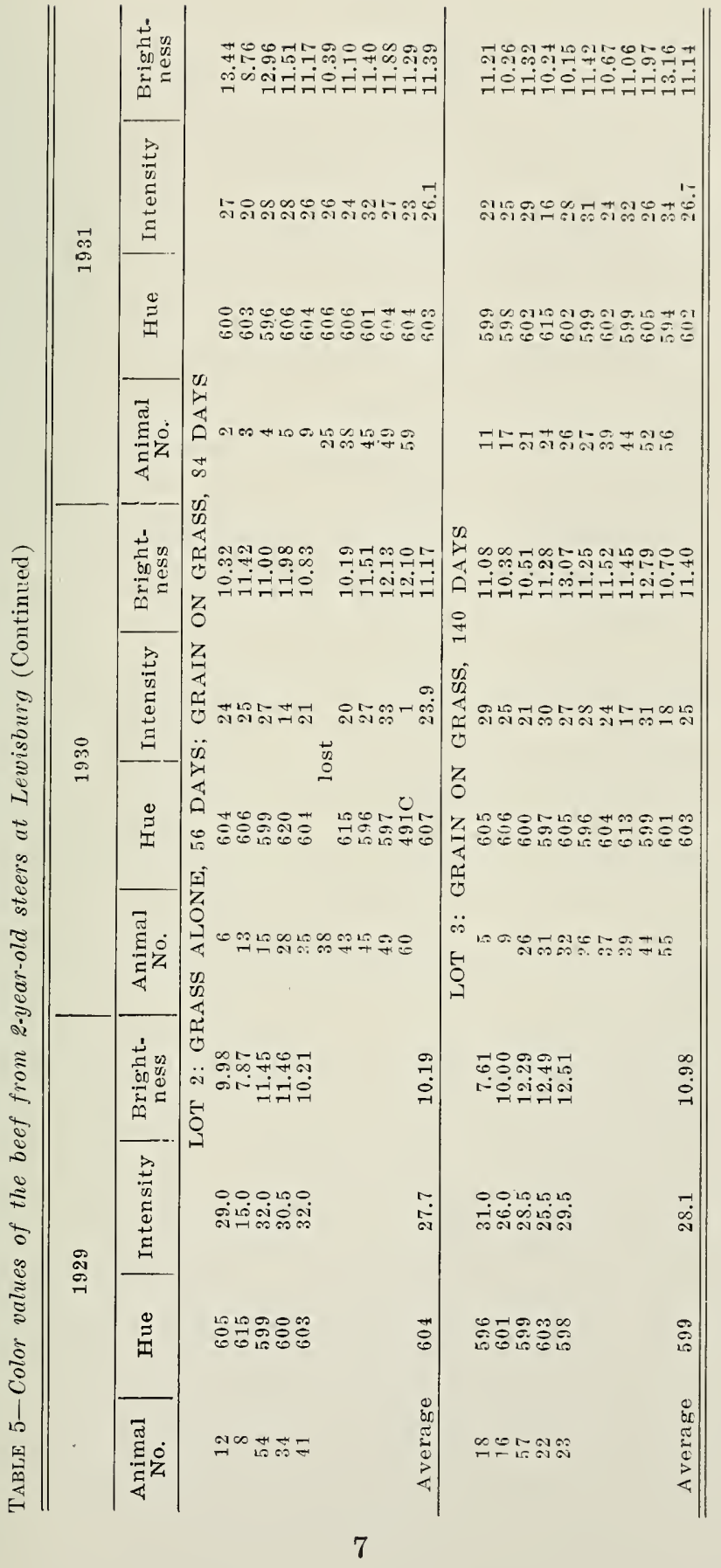


color value most closely related to the color as seen with the eye. None of these steers killed dark enough to be objectionable.

Among the Lewisburg cattle (Table 5) no differences attributable to feed appeared in 1929, although there were one or two dark carcasses in each lot. In 1930 all the cattle from Lewisburg killed bright. The beef from Lots 1-B and 1-C was noticeably brighter than that from the other three lots. The cattle in Lots 1-B and 1-C were fed grain after the grazing season and had more finish when killed than did those in the other lots. In 1931 the beef from Lots 2 and 3 appeared to be slightly brighter, but this difference was so small as to be negligible. The high values for hue and the appearance of several purple carcasses in Lots 1-B and 1-C constituted the main differences between the lots for this year. The available information provides no satisfactory explanation for the color of the beef from these two lots.

The color values of beef from the two-year-old steers, 186 in all, give no indications of any effect of feed on the color of lean. A few of these cattle killed dark, but these dark cutters occurred in different lots without any apparent relation to the feed consumed. There were but a few of these dark cutters, most of the beef being bright, regardless of the amount of grass or grain eaten. There was some indication of a relationship between brightness of lean and degree of finish, those cattle showing the higher degree of finish having the brightest lean. The differences in degree of finish and in brightness of lean were so small in the two-year-old steers that this relationship was not very pronounced. The fat yearlings carried considerably more finish than any of the other cattle and they showed a brighter lean than the two- or three-year-old cattle. Young cattle commonly show brighter lean than older cattle of the same degree of finish, for the older the cattle, the darker the color. A part of this greater degree of brightness in the yearlings probably is attributable to their youth.

Work done at other stations, especially Illinois (1) and Kansas (2), shows these same relationships between age, degree of finish, and brightness of beef.

The experimental evidence obtained does not substantiate the idea that grass as a feed produces dark lean in becf. Well-finished grass-fed cattle can be expected to kill as bright as grain-fed cattle of the same degree of finish.

\section{Summary}

Grass as a feed was not found to produce dark lean in beef.

The brightness of the lean of beef appears to be related directly to the degree of finish of the beef.

Beef from grass-finished cattle can be expected to be as bright as beef from grain-finished cattle which show a comparable degree of finish.

(1) Bull, Sleeter. An. Report, Ill. Agr. Expt. Sta. 1928-29.

(2) Mackintosh, D. L. Bien. Report, Kans. Agr. Expt. Sta. 1928-30.

NOTE: The two-year-old steers fed at Lewisburg, from which beef samples were obtained, were included in Project P-7, a cooperative project between the Federal Bureau of Animal Industry and the W. Va. Agricultural Experiment Station. The author wishes to express his appreciation to those members of the Bureau whose cooperation made possible the collection of these data at Beltsville, Md. 
